\title{
Effect of tryptase on mouse brain microvascular endothelial cells via protease-activated receptor 2
}

\author{
Qin Zhou ${ }^{\dagger}$, Yi-wei Wang ${ }^{\dagger}$, Peng-fei Ni, Yi-nan Chen, Hong-quan Dong and Yan-ning Qian ${ }^{*}$ (D)
}

\begin{abstract}
Background: Mast cells (MCs), the 'first responders' in brain injury, are able to disrupt the blood-brain barrier (BBB), but the underlying mechanism is not well understood. Tryptase is the most abundant MC secretory product. Protease-activated receptor 2 (PAR-2) has been identified as a specific receptor for tryptase, which is abundantly expressed in brain microvascular endothelial cells. The BBB comprises brain microvascular endothelial cells that display specialised molecular properties essential for BBB function and integrity. Therefore, the purpose of the present study was to investigate the effects of tryptase on mouse brain microvascular endothelial cell line bEnd3 and its potential mechanisms of action.

Methods: Induction of mouse brain microvascular endothelial cell activation by tryptase was examined. Then, mouse brain microvascular endothelial cells were pretreated with a PAR-2 antagonist and stimulated with tryptase. Cellular activation, proinflammatory cytokine production, expression of PAR-2, Toll-like receptors (TLRs) and mitogen-activated protein kinases (MAPK), nuclear factor kappa B (NF-kappa B) phosphorylation were assessed.

Results: Tryptase upregulated the production of VCAM-1, MMPs (MMP9 and MMP2), TLR4 and TNF-a and downregulated the expression of the tight junction proteins occludin and claudin-5 in mouse brain microvascular endothelial cell. Among the MAPK and NF-kappa B pathway, ERK and NF-kappa B were activated by tryptase. All of these effects could be eliminated by the PAR-2 inhibitor.

Conclusion: Based on our findings, we conclude that tryptase can trigger brain microvascular endothelial cell activation and proinflammatory mediator release. These findings may further clarify the involvement and mechanism of tryptase in BBB disruption.
\end{abstract}

Keywords: Brain microvascular endothelial cells, Tryptase, Protease-activated receptor 2 (PAR-2), MAPK, NF-kappa B

\section{Background}

Mast cells (MCs) are multifunctional immune cells that can maintain and regulate immune function, best known for the important role in allergic inflammation [1]. There is increasing evidence showing that $\mathrm{MC}$ degranulation in the brain is involved in central nervous system (CNS) inflammatory processes [2-4]. However, the mechanisms underlying how mast cells disrupt the BBB are unclear.

Tryptase is the major secretory protein of mast cell degranulation [5]. Upon activation, MCs secrete tryptase,

\footnotetext{
*Correspondence: yanning_qian@163.com

${ }^{\dagger}$ Qin Zhou and Yi-wei Wang contributed equally to this work.

Department of Anesthesiology, The First Affiliated Hospital of Nanjing

Medical University, Nanjing 210029, Jiangsu, People's Republic of China
}

which can contribute to microvascular leakage in guinea pigs and induce the recruitment of inflammatory cells in the peritonea of mice $[6,7]$. It can also stimulate peripheral mononuclear cells to release interleukin-6 (IL-6) and tumour necrosis factor-alpha [8]. In vitro, tryptase can contribute to microglia and astrocyte activation and release of proinflammatory mediators via mitogen-activated protein kinases (MAPK) and nuclear factor kappa B (NF-kappa B) $[9,10]$. These observations indicate that tryptase has a vital role in MC-associated inflammation.

Recent studies have found that PAR-2 is widely expressed in the brain, including the $\mathrm{BBB}$ and cerebral microvascular endothelial cells. Furthermore, the activation of PAR-2 is associated with neuroinflammation and

(c) The Author(s). 2018 Open Access This article is distributed under the terms of the Creative Commons Attribution 4.0 International License (http://creativecommons.org/licenses/by/4.0/), which permits unrestricted use, distribution, and reproduction in any medium, provided you give appropriate credit to the original author(s) and the source, provide a link to the Creative Commons license, and indicate if changes were made. The Creative Commons Public Domain Dedication waiver (http://creativecommons.org/publicdomain/zero/1.0/) applies to the data made available in this article, unless otherwise stated. 
neurodegenerative diseases [11, 12]. Reports have showed that PAR-2 activation can contribute to microglial activation, which induces neuronal cell death, and activation of PAR-2 destroys the BBB during cerebral damage $[13,14]$.

Cerebral microvascular endothelial cells are the major components of the BBB and tight junction protein (TJP) network produced by endothelial cells to maintain the integrity of the BBB $[11,15]$. A report showed TJP degradation increases endothelial cell permeability, destroying BBB integrity [16]. Cerebral microvascular endothelial cells can also express matrix metalloproteinases (MMPs), which are markers of inflammation. Matrix metalloproteinase 2 (MMP2) and MMP9 can degrade TJPs, disrupting the integrity of the BBB [17].

We previously demonstrated that $\mathrm{MC}$ degranulation can disrupt the BBB [4]. We also found that the supernatant from activated MCs can induce mouse brain microvascular endothelial cell activation and promote the secretion of the inflammatory cytokines TNF- $\alpha$ and IL-6. However, the effect of MC tryptase on mouse brain microvascular endothelial cell has not yet been studied. In the present study, we investigated the possibility that tryptase could trigger mouse brain microvascular endothelial cell activation through PAR-2.

\section{Methods}

\section{Reagents}

Dulbecco's modified Eagle's medium (DMEM), foetal bovine serum (FBS) and $0.25 \%$ Trypsin-EDTA solution were purchased from Gibco-BRL (Grand Island, NY, USA). Tryptase was purchased from Sigma-Aldrich (St. Louis, MO, USA), and it is the human lung tryptase, which is a neutral serine protease and the predominant protein in mast cell granules. PAR-2 inhibitor FSLLRY-NH2 (FS) was synthesised by CL Bio-Scientific Inc. (Xi An, China). CCK-8, RIPA buffer and the BCA kit were purchased from Beyotime (Shanghai, China). Rabbit anti-PAR-2 polyclonal antibody and fluoroshield mounting medium with 4',6-diami-dino-2-phenylindole (DAPI) were purchased from Abcam (Hongkong, China). Anti-TLR4 monoclonal antibody, anti-VCAM-1 antibody (EPR5 047) and anti-occludin antibody (EPR8208) were purchased from Abcam (Hongkong, China). AntiGAPDH antibody was purchased from Bioworld Technology, Inc. (USA). Anti-p44/42 MAPK monoclonal antibody (extracellular regulated protein kinases, ERK), anti-Phosphop44/42 monoclonal antibody (phosphoERK) and NF-kappa B were purchased from Cell Signaling (Beverly, MA, USA).Anti-rabbit and anti-mouse secondary antibodies were all purchased from Jackson Immuno Research Laboratories Inc. (Boston, MA, USA).

\section{Cell cultures}

The mouse brain microvascular endothelial cell line bEnd.3 was purchased from Shanghai Bioleaf (Shanghai,
China). bEnd.3 cells were cultured in DMEM (Thermo Fisher Scientific, Waltham, MA,USA) containing 10\% foetal bovine serum (FBS), $100 \mu \mathrm{g} / \mathrm{mL}$ penicillin and $100 \mu \mathrm{g} / \mathrm{mL}$ streptomycin $(\mathrm{pH}=7.2-7.4)[16,18]$. The cells were seeded on poly-D-lysine pre-coated cell culture flasks and cultured at $37{ }^{\circ} \mathrm{C}$ in a humidified atmosphere of $5 \%$ $\mathrm{CO} 2 / 95 \%$ air. Two-milliliter medium was given to the cells. The medium was replaced every 2 to 3 days after seeding. They were passaged at the same density until the cell confluence reached $80 \%$. The cells were starved overnight and then subjected to treatments and were pretreated with FS $(400 \mu \mathrm{M})$ for 30 min before tryptase $(1 \mu \mathrm{g} / \mathrm{mL})$ stimulation, and the volume of tryptase was $1 \mu \mathrm{L}$ (the concentration of tryptase is $2 \mu \mathrm{g} / \mu \mathrm{L}$ ). This experiment consists of four groups (control group, tryptase group, FS group, tryptase + FS group). We dissolved tryptase and FS in PBS, so we also added the same volume of the PBS in the control group.

\section{Cell viability}

In order to measure the toxicity of tryptase and FS to mouse brain microvascular endothelial cell, experimental groups were divided into eight groups receiving different concentrations of tryptase $(0.001,0.01,0.1,1$, and $10 \mu \mathrm{g} /$ $\mathrm{mL})[9,10]$, FS $(400 \mu \mathrm{M}, 800 \mu \mathrm{M})[5,9,10]$ and control group. We added the same volume of the PBS to the control group. Briefly, mouse brain microvascular endothelial cell were seeded into 96-well plates at a density of 5000 cells/well, and $100 \mu \mathrm{L}$ of the medium was added to each well. Twenty-four hours after the incubation, the medium was discarded and $100 \mu \mathrm{L}$ of fresh medium was added to the normal control groups. Media containing tryptase and FS of different concentrations were added to experimental groups. After $24 \mathrm{~h}$, the WST-8 dye (Water-soluble tetrazoliuM-8,Cell Counting Kit-8, CCK-8 main components) was added to each well, and the cells were then incubated at $37^{\circ} \mathrm{C}$ for $2 \mathrm{~h}$. The absorbance was determined at $450 \mathrm{~nm}$ using a microplate reader.

\section{Western blotting}

Cellular proteins were extracted by RIPA buffer after mouse brain microvascular endothelial cells were stimulated by drugs for $24 \mathrm{~h}$. A BCA kit was used to measure the protein concentration in the lysate supernatant. Cell extract proteins $(50 \mu \mathrm{g})$ were denatured with sodium dodecyl sulfate (SDS) sample buffer and separated using $10 \%$ SDS-polyacrylamide gel electrophoresis (PAGE). The proteins were transferred to a polyvinylidene fluoride (PVDF) microporous membrane (Millipore, Bedford, MA, USA), which was then blocked with $5 \%$ skim milk for $1 \mathrm{~h}$ at room temperature. The membrane was incubated with primary antibody overnight at $4{ }^{\circ} \mathrm{C}$. The following primary antibodies were used: rabbit monoclonal anti-PAR-2 (Abcam, EPR13675, 1:1000), rabbit monoclonal 
anti-VCAM-1 (Abcam, EPR5047, ab134047, 1:2000), rabbit monoclonal anti-GAPDH (Bioworld Technology Inc., Ap0063, 1:1000), rabbit monoclonal anti-MMP-9 (Abcam, 1:500), rabbit monoclonal anti-MMP-2 (Abcam, 1:1000), rabbit monoclonal anti-occludin (Abcam, EPR8208, ab167161, 1:50,000), mouse monoclonal anti-claudin-5 (Invitrogen, 1:500), and mouse monoclonal anti-TLR4 (Abcam, 76B357.1, ab22048, $4 \mu \mathrm{g} / \mathrm{ml}$ ). After adding the anti-rabbit or anti-mouse secondary antibody (Jackson Immuno Research Laboratories INC. number: 122825 and 122627, 1:1000) for $1 \mathrm{~h}$, protein bands on the membranes were detected using an enhanced chemiluminescence kit. The relative density of the protein bands was obtained by densitometry using Image Lab software (Bio-Rad, Richmond, CA, USA) and quantified using NIH ImageJ software (Bethesda, MD, USA).

\section{Immunofluorescence}

To examine the activation of the mouse brain microvascular endothelial cell and the expression of PAR-2, cells were fixed with $4 \%$ paraformaldehyde for $30 \mathrm{~min}$. Non-specific binding was blocked by incubating cells in a 5\% BSA and $0.1 \%$ Triton X-100 solution for $1 \mathrm{~h}$ at room temperature. Mouse brain microvascular endothelial cells were incubated with rabbit anti-VCAM-1 polyclonal antibody (1:200) or rabbit anti-PAR-2 polyclonal antibody (1:100) in the blocking solution overnight at $4{ }^{\circ} \mathrm{C}$. After three washes with PBS, mouse brain microvascular endothelial cells were incubated with the corresponding FITC-conjugated goat anti-rabbit IgG (1:200) for $2 \mathrm{~h}$ at room temperature. Nuclei were stained with DAPI. Fluorescent images were acquired using a confocal microscope.

\section{Enzyme-linked immunosorbent assay (ELISA)}

The amount of TNF- $\alpha$ in the culture medium was measured using a commercial ELISA kit from R\&D Systems (Minneapolis, MN, USA) according to the manufacturer's instructions.

\section{Real-time PCR}

Total RNA was extracted from mouse brain microvascular endothelial cell cultures using Trizol Reagent (Invitrogen), and reverse transcription was performed from $1 \mu \mathrm{g}$ of total RNA for each sample using the Transcription First Strand cDNA Synthesis Kits (Roche) according to the manufacturer's instructions. Real-time PCR amplification was performed using the StepOne Plus Real-Time PCR System (Applied Biosystems) with the SYBR Green master mix (Applied Biosystems, Foster City, CA) in a final volume of $10 \mu \mathrm{g}$ that contained $1 \mu \mathrm{g}$ of cDNA template from each sample. Primers used were as follows: mouse GAPDH forward, 5' -AACTTTGGCATTGTGGAAGG-3', and reverse, 5'-GGATGCAGGG- ATGATGTTCT-3'; mouse TNF- $\alpha$ forward, $5^{\prime}$-GACGTGGAACTGGCA- GAAG
AG-3'; and reverse, 5'-TTGGTGGTTTGTGAGTGTG AG-3'. The cycling conditions were $95{ }^{\circ} \mathrm{C}$ for $10 \mathrm{~min}$, followed by 40 cycles of $95{ }^{\circ} \mathrm{C}$ for $15 \mathrm{~s}$ and $60{ }^{\circ} \mathrm{C}$ for $1 \mathrm{~min}$. The relative mRNA values were normalised to GAPDH gene control values and calculated using the comparative cycle threshold $(\Delta \Delta \mathrm{Ct})$ method.

\section{Statistical analysis}

All values are expressed as the mean \pm S.E.M. Statistical analysis was carried out with GraphPad Prism 5 software (version 5.01, GraphPad Software, San Diego, CA). Data were analysed with one-way ANOVA, followed by Newman-Keuls post hoc testing where appropriate. Statistical significance was accepted at $p<0.05$.

\section{Results}

Effects of tryptase and FS on cell viability in mouse brain microvascular endothelial cell

The Cell Counting Kit-8 (CCK-8) assay was used to evaluate the toxic effects of tryptase and FS (a PAR-2 inhibitor) on mouse brain microvascular endothelial cell. The mouse brain microvascular endothelial cells were divided into eight groups, including different concentrations of tryptase $(0.001,0.01,0.1,1$ and $10 \mu \mathrm{g} / \mathrm{mL})$, FS $(400 \mu \mathrm{M}$, $800 \mu \mathrm{M})$ and control group. Then cell viability was measured by the CCK- 8 assay after incubating $24 \mathrm{~h}$. Our results indicate that tryptase $(1 \mu \mathrm{g} / \mathrm{mL})$ and $400 \mathrm{uM} \mathrm{FS}$ exerted no obvious toxic effects on mouse brain microvascular endothelial cell (Fig. 1).

\section{Tryptase can promote the expression of PAR-2 on mouse} brain microvascular endothelial cell

As tryptase is the natural agonist of PAR-2, we examined the influence of tryptase on the expression of PAR-2 by western blotting and immunofluorescence. As shown in Fig. 2a, b, tryptase could upregulate the protein level of PAR-2. However, pre-treatment with FS (a PAR-2 inhibitor)

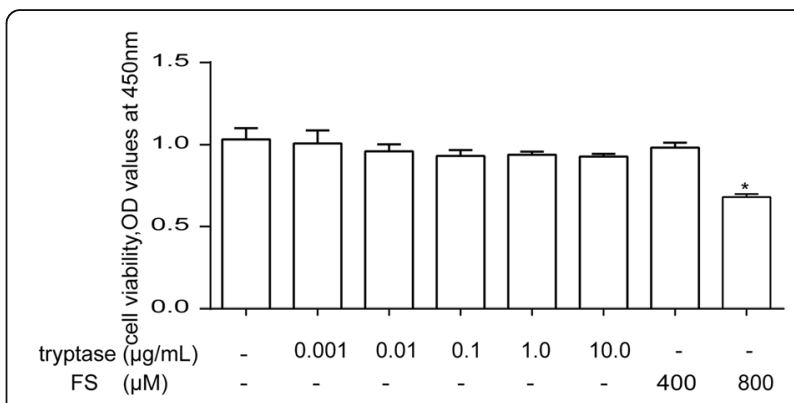

Fig. 1 The effects of tryptase and FS on cell viability in mouse brain microvascular endothelial cell. Mouse brain microvascular endothelial cells were exposed to different concentrations of tryptase $(0.001,0.01$, $0.1,1$, and $10 \mu \mathrm{g} / \mathrm{mL})$ and $\mathrm{FS}(400 \mu \mathrm{M}, 800 \mu \mathrm{M})$ and control group for $24 \mathrm{~h}$. Cell viability was determined using a colorimetric method. ${ }^{*} P<0.05$ versus the control group. Each data point represents the mean \pm S.E.M of at least three separate experiments 


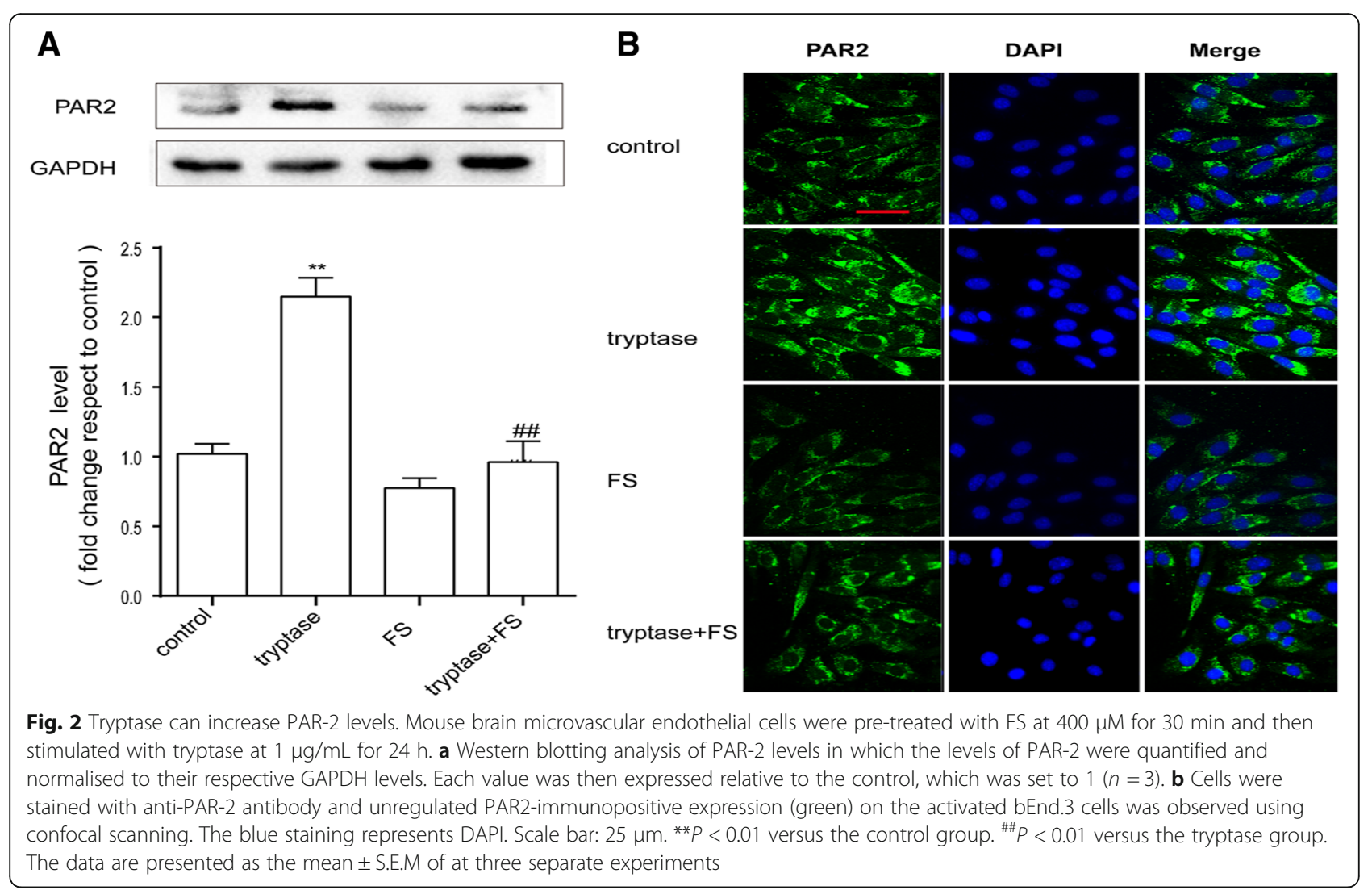

resulted in decreased expression of PAR-2 compared with the control group.

Tryptase upregulates the production of VCAM-1 via PAR-2 To confirm that mouse brain microvascular endothelial cell activation was induced by tryptase, we used western blotting and immunofluorescence to examine the expression of the adhesion molecule VCAM-1. Cells were pretreated with FS $(400 \mu \mathrm{M})$ for $30 \mathrm{~min}$ and then stimulated with tryptase $(1 \mu \mathrm{g} / \mathrm{ml})$ for $24 \mathrm{~h}$. Western blotting results showed that tryptase significantly upregulated the expression of VCAM-1 (Fig. 3a). Immunofluorescence results also showed that compared with the control group, tryptase significantly increased VCAM-1 levels (Fig. 3b). However, pre-incubation with FS could reverse this phenomenon.

\section{Effect of tryptase on the production of occludin and claudin-5}

We used western blotting to examine the expression of the tight junction proteins occludin and claudin-5, which are associated with BBB integrity. As shown in Fig. 4, following incubation with tryptase at $1 \mu \mathrm{g} / \mathrm{ml}$ for $24 \mathrm{~h}$, the production of proteins from mouse brain microvascular endothelial cell clearly decreased compared with the control group. Pre-incubation with FS $(400 \mu \mathrm{M})$ for $30 \mathrm{~min}$ could eliminate these effects.

\section{Tryptase can upregulate the production of MMP2 and MMP9}

MMPs regulate the expression of occludin family members and are markers of inflammation. Therefore, we next examined the effect of tryptase on the production of MMPs, especially MMP-9 and MMP-2. As shown in Fig. 5, after stimulation with tryptase at $1 \mu \mathrm{g} / \mathrm{ml}$ for $24 \mathrm{~h}$, MMP-9 and MMP-2 levels increased compared with the control group. Pre-incubation with FS $(400 \mu \mathrm{M})$ for 30 min could reverse this phenomenon.

\section{Tryptase activated MAPK and NF-kappa B pathway and promoted cytokine production via PAR-2}

In order to further study the action of tryptase on mouse brain microvascular endothelial cells, we examined the effect of tryptase on phosphorylation of cell signalling molecules. Endothelial cells were pre-treated with PAR-2 antagonist $\mathrm{FS}(400 \mu \mathrm{M})$ for $30 \mathrm{~min}$ and then stimulated by tryptase $(1 \mu \mathrm{g} / \mathrm{ml})$ for another $30 \mathrm{~min}$ for examining phosphorylation of ERK and NF-kappa B p65. As shown in Fig. 6a, b, tryptase induced a high phosphorylation of ERK and NF-kappa B p65 compared with control group, which was inhibited by PAR-2 antagonist FS. To observe inflammation effects of tryptase, proinflammation factor TNF- $\alpha$ and TLR4 were determined, respectively. Figure $6 c-e$ shows that tryptase could promote the expression of TNF$\alpha$ and TLR4. FS counteracted this increase as well. These 


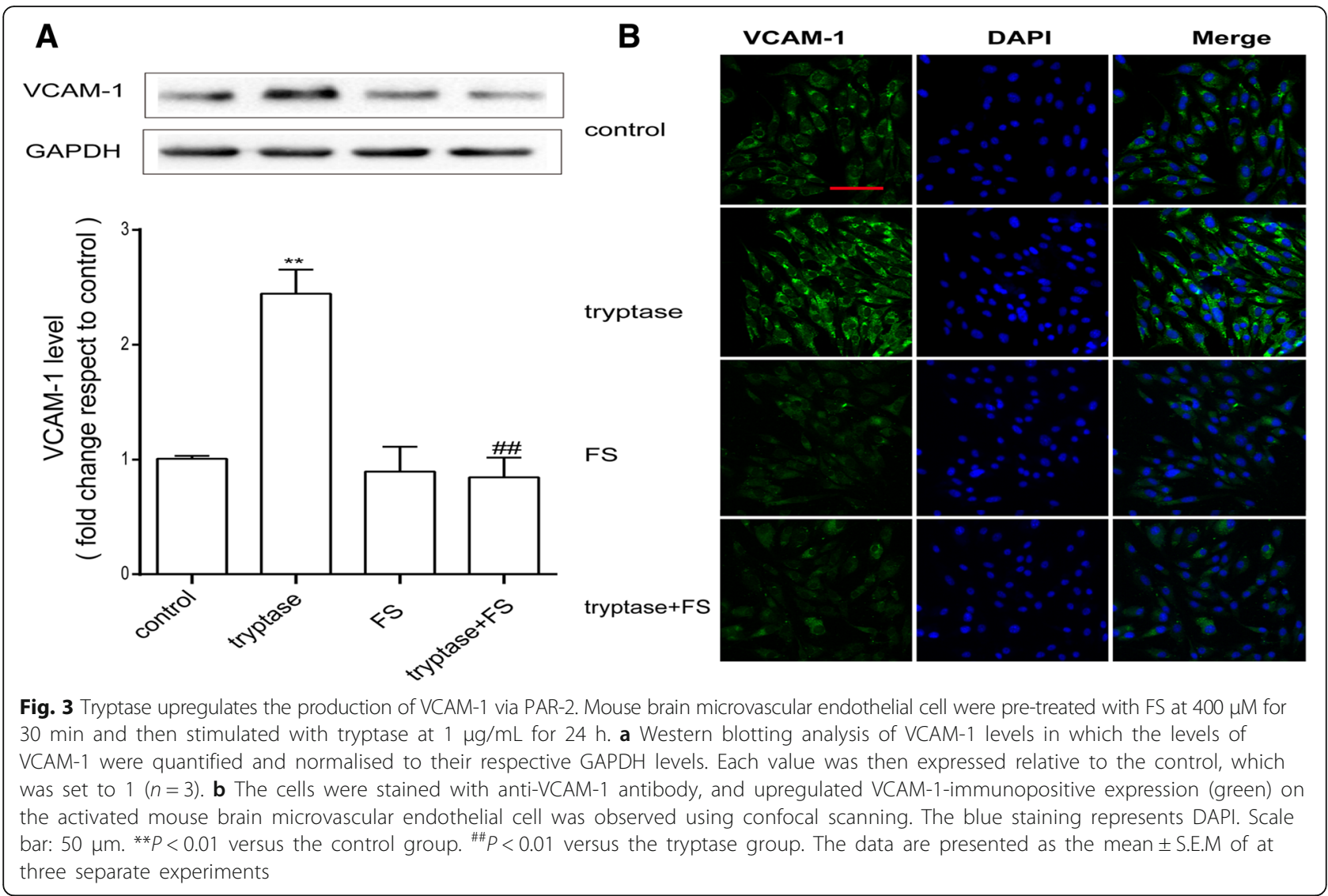

A
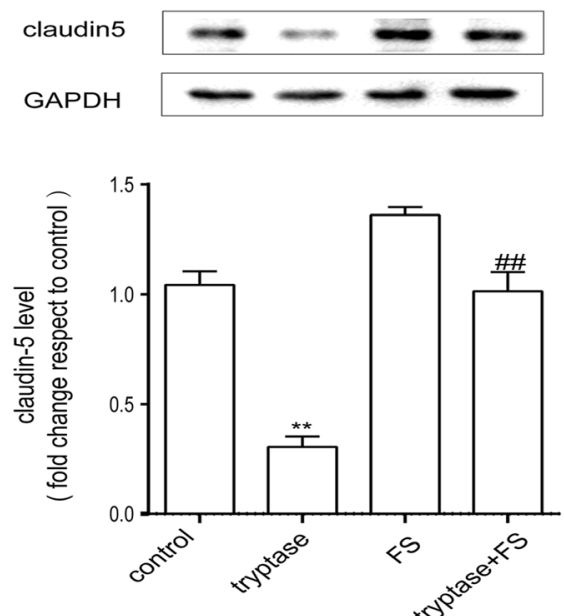

B

occludin

GAPDH
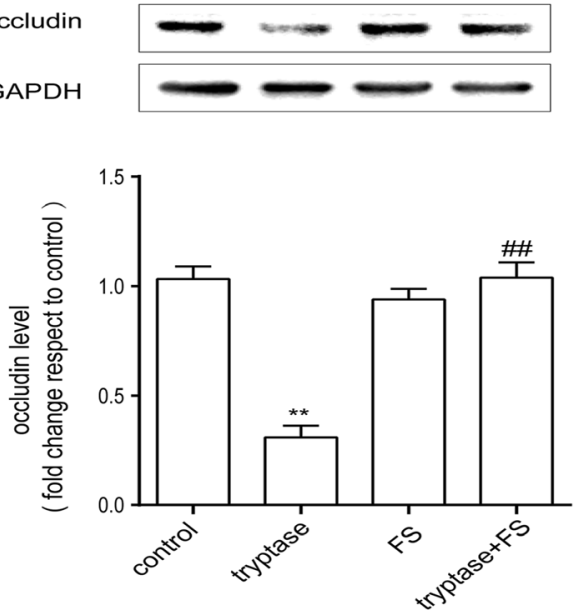

Fig. 4 Tryptase can downregulate the production of tight-junction proteins. Mouse brain microvascular endothelial cells were accordingly pretreated with FS at $400 \mu \mathrm{M}$ for $30 \mathrm{~min}$ and then stimulated with tryptase at $1 \mu \mathrm{g} / \mathrm{ml}$ for $24 \mathrm{~h}$. a, b Western blotting analysis of claudin-5 and occludin levels, which were quantified and normalised to the respective GAPDH. Each value was then expressed relative to the control, which was set to $1(n=3)$. ${ }^{*} p<0.01$ versus the control group. ${ }^{\#} P<0.01$ versus the tryptase group. The data are presented as the mean \pm S.E.M of at three separate experiments 

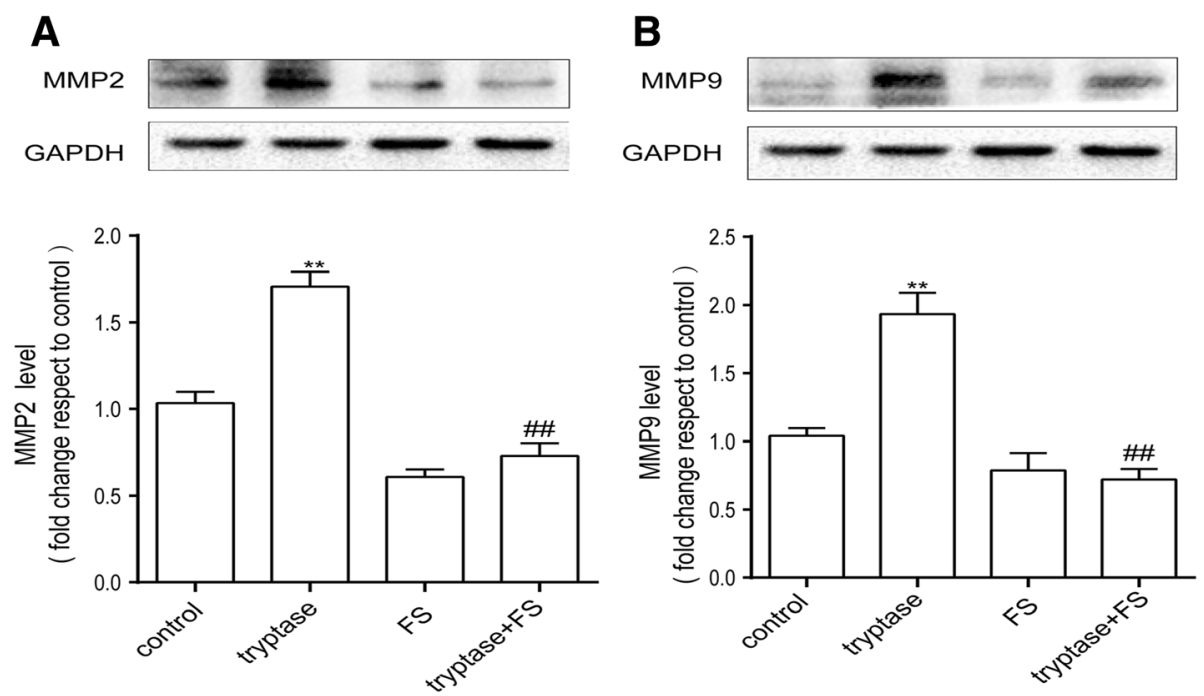

Fig. 5 Tryptase could upregulate the production of MMP-9 and MMP-2. Mouse brain microvascular endothelial cell were accordingly pretreated with FS at $400 \mu \mathrm{M}$ for $30 \mathrm{~min}$ and then stimulated with tryptase at $1 \mu \mathrm{g} / \mathrm{ml}$ for $24 \mathrm{~h}$. $\mathbf{a}$, b Western blotting analysis of MMP-9 and MMP-2 levels, which were quantified and normalised to their respective GAPDH levels. Each value was then expressed relative to the control, which was set to $1(n=3)$. ${ }^{*} P<0.01$ versus the control group. ${ }^{\# \#} P<0.05$ versus the tryptase group. The data are presented as the mean \pm S.E.M of at three separate experiments

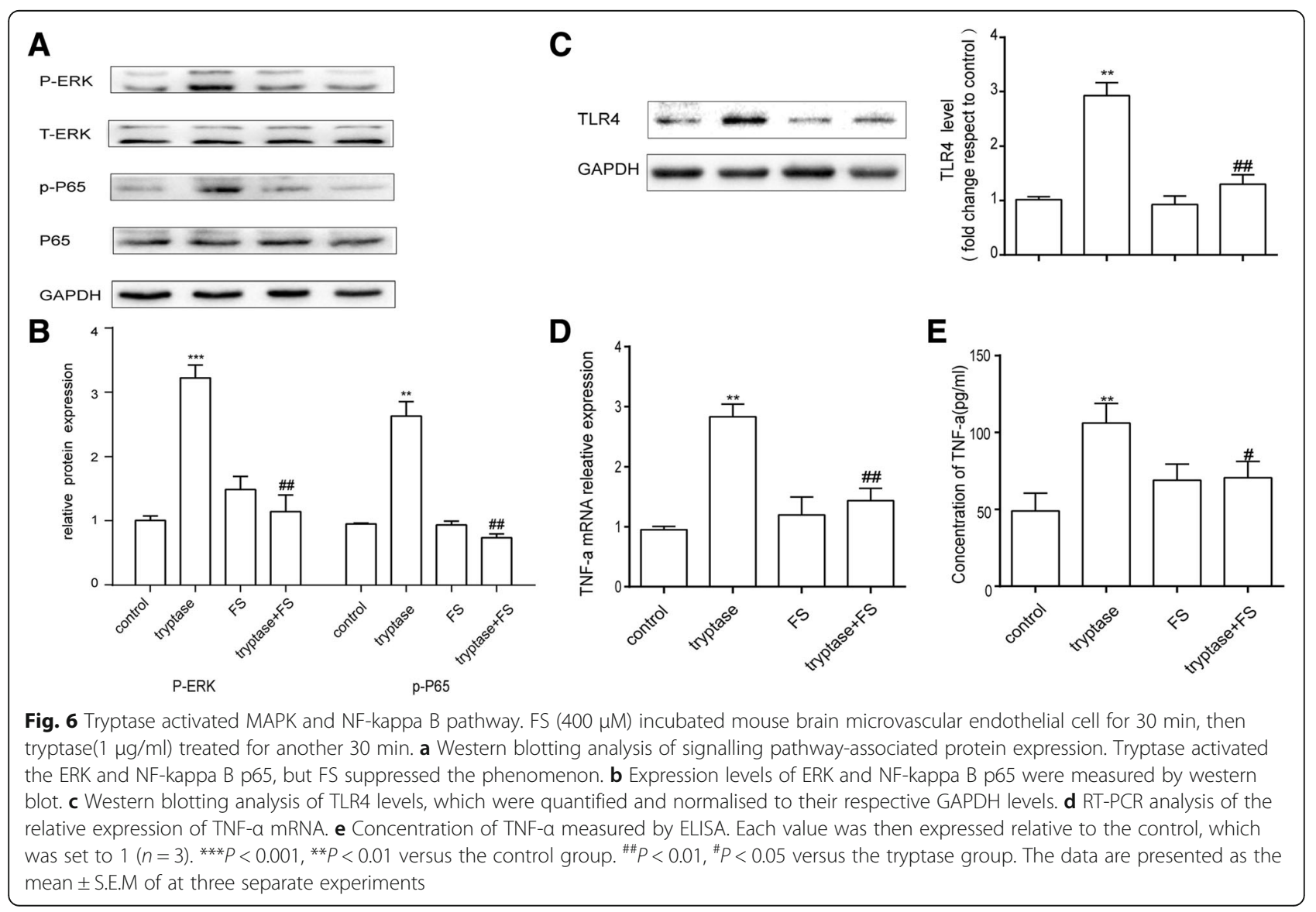


phenomenons show that tryptase activates ERK-MAPK and NF-kappa B p65 signalling pathway and promotes the inflammation mediator secretion via PAR-2.

\section{Discussion}

The BBB maintains an optimum ionic composition of cerebrospinal fluid (CSF), which limits the entry of plasma components and supports the unique metabolic needs of the brain, providing a stable environment for proper brain function. Disruption of the BBB has been proven to be related to various neurological disorders, such as Alzheimer's disease (AD), Parkinson's disease (PD), and postoperative cognitive dysfunction (POCD) $[19,20]$. In the early stages of the pathogenesis of acute cerebral ischaemia and cerebral haemorrhage, mast cells exhibit the rapid degranulation response in cerebral blood vessels and other parts of the CNS, releasing vasoactive and neuroactive synthetic medium in advance. The active medium acts on the basement membrane to disrupt the BBB and brain oedema, promoting the infiltration of cells and haemorrhage [2]. In addition, in acute cerebral ischaemia injury, brain mast cells increase in number, which prolongs the expression of endothelial cell adhesion molecules, destroys the $\mathrm{BBB}$ and recruits neutrophils, macrophages and other inflammatory cells into the centre of the injury [21, 22].Therefore, MCs play a vital role in the disruption of the BBB, but the details of how they work are still unknown. Thus, in the present work, we focused on bEnd. 3 cells with an emphasis on their potential role in BBB integrity.

The current study demonstrated for the first time that stimulation of PAR-2 on bEnd.3 cells with tryptase triggered the activation of mouse brain microvascular endothelial cell and resulted in the degradation of occludin and claudin-5, increasing the production of the inflammatory mediators MMP-9, MMP-2 and TNF- $\alpha$. The signalling pathway MAPK-NF-kappa B is associated with the tryptase-induced PAR-2 activation. However, FS could eliminate the effect of tryptase on the bEnd. 3 cells. The result of CCK8 showed that the concentration of FS $(800 \mu \mathrm{M})$ is toxic to bEnd. 3 cells, so we chosed the concentration of FS $(400 \mu \mathrm{M})$ to stimulate the cells.

VCAM-1 is a symptom of endothelial cell activation and is associated with mononuclear cell adhesion and immune cell transmigration [23]. Brain microvascular endothelial cells are important sources of VCAM-1. The reports demonstrated that cerebral endothelial cells could express VCAM-1 and contribute to lymphocyte adhesion and upregulation of VCAM-1 on endothelial cells could promote T cell transmigration [24, 25]. A considerable amount of evidence suggests the expression of VCAM- 1 is linked to brain endothelial cell activation and immune cell transmigration. Like VCAM-1, matrix metalloproteinases (MMPs), especially MMP-2 and MMP-9, appear to also play an important role in the early disruption of the BBB $[26,27]$. MMPs are markers of inflammation, and upon activation, MMPs can degrade most of the protein constituents of the neurovascular matrix, such as elastin, collagen, fibronectin, vitronectin, and gelatin [28]. Here, we found that tryptase increased VCAM-1 and MMP secretion by mouse brain microvascular endothelial cell. However, FS (PAR-2 antagonist) was able to block the secretion of VCAM-1, MMP-9 and MMP-2. PAR-2 was found to be expressed abundantly on brain microvascular endothelial cell, and PAR-2 activation in endothelial cell has been demonstrated to play a key modulatory role in diverse pathological conditions $[11,12]$.

Tryptase, a major MC secretory protein, is an endogenous peptide. Tryptase is involved in angiogenesis after they are secreted from activated MC granules and its proteolytic activities release matrix-associated growth factors or degrade extracellular matrix components associated with a critical step in the early stages of angiogenesis as well as during invasion and metastasis of tumour cells [29]. So tryptase is a novel angiogenesis factor, which also specifically activates PAR-2 [5]. In our study, we found that incubation with tryptase decreased the expression of claudin- 5 and occludin in mouse brain microvascular endothelial cell. FS (a PAR-2 antagonist) diminished the effect of tryptase on claudin-5 and occludin expression, implying that the inhibition of claudin-5 and occludin by tryptase may at least partially be responsible for the activation of PAR-2. In the brain, tight junction proteins such as claudin- 5 and occludin at the lateral apical membrane establish a high-resistance paracellular barrier to small hydrophilic molecules and ions. There is increasing evidence supporting a role for TJ-associated proteins in the permeability and integrity of the BBB $[15,16]$. Reports have found that degradation of claudin-5 and occludin can increase the permeability and contribute to brain oedema in ischaemic stroke [30]. And claudin-5 regulates the permeability and integrity of the BBB by changing endothelial or epithelial cell permeability [31]. Our current observation suggests that moderate stimulation of PAR-2 on mouse brain microvascular endothelial cell may regulate tight junction proteins and supply a new option for the management of CNS functions.

TJP-occludin and claudin- 5 produced by brain endothelial cells are good for the BBB, but brain endothelial cells also play an important role in regulating inflammatory responses at the $\mathrm{BBB}$ by releasing cytokines. Brain endothelial cells could synthesise CCL2 and CCL3 with significant upregulation after LPS activation [32]. Recent studies have found that activation of PAR-2 is also associated with inflammation [33, 34]. In type 2 diabetic mice, stimulation of PAR-2 can upregulate TNF- $\alpha$ expression [35]. MAPK and NF-kappa B signalling pathway are associated with the inflammation progress in endothelial cells [36]. Therefore, we examined the expression of TLR4 and TNF- $\alpha$ and MAPK 
and NF-kappa B signalling pathway-associated protein when PAR-2 on mouse brain microvascular endothelial cell was stimulated by tryptase. Our results were similar to those of previous reports that the stimulation of PAR-2 promotes secretion of the inflammatory cytokine TNF- $\alpha$ and upregulates the level of TLR4 and activates ERK and NF- kappa B p65. However, FS (a PAR-2 antagonist) could protect mouse brain microvascular endothelial cell by inhibiting TNF- $\alpha$ secretion and phosphorylation of ERK and NF-kappa B p65.

\section{Conclusion}

In conclusion, to our knowledge, this is the first study to demonstrate the ability of mast cell tryptase to modulate mouse brain microvascular endothelial cell activation and inflammatory factor production via PAR-2. The possible intracellular signalling mechanisms are PAR-2-MAPKNF-kappa B pathway. The results of these experiments provide evidence that tryptase-induced mouse brain microvascular endothelial cell activation may be involved in the disruption that occurs in neurodegenerative diseases.

\section{Abbreviations \\ BBB: Blood-brain barrier; CNS: Central nervous system; IL-6: Interleukin-6; MC: Mast cell; MMP2: Matrix metalloproteinase 2; MMP9: Matrix metalloproteinase 9; PAR-2: Protease-activated receptor 2; POCD: Postoperative cognitive dysfunction; TJP: Tight junction protein; TLR4: Toll-like receptor-4; TNF-a: Tumour necrosis factor-a; CCK-8: Cell counting Kit-8; ELISA: Enzyme-linked immunosorbent assay; FS: FSLLRY-NH2; MAPK: Mitogen-activated protein kinases; ERK: Extracellular regulated protein kinases; NF-kappa B: Nuclear factor kappa B; PBS: Phosphate buffer saline}

\section{Acknowledgements}

We thank Prof. Huafeng Wei (Department of Anesthesiology and Critical Care, Perelman School of Medicine, University of Pennsylvania, Philadelphia, PA, 19104, USA) for his experiment guidance.

\section{Funding}

This project was sponsored by the National Natural Science Foundation of China (No. 81671387, 81471410, 81701375), Postgraduate Research \& Practice Innovation Program of Jiangsu Province(KYCX17_1250) and a Project Funded by the Priority Academic Program Development of Jiangsu Higher Education Institutions (PAPD).

\section{Availability of data and materials}

The datasets supporting the conclusions of this article are included within the article and its additional files. All materials used in this manuscript will be made available to researchers subject to confidentiality.

\section{Authors' contributions}

QZ, YW, PN, CY and DH performed the experiments; QZ, YW and YQ designed the study; and QZ wrote the manuscript. All authors read and approved the final manuscript.

\section{Ethics approval and consent to participate}

The experiments were approved by the Nanjing Medical University Institutional Animal Care and Use Committee (IACUC-14030126), and the experiments were performed according to the Guide for the Care and Use of Laboratory Animals of the National Institutes of Health of the United States.

\section{Consent for publication}

Not applicable.

\section{Competing interests}

The authors declare that they have no competing interests.

\section{Publisher's Note}

Springer Nature remains neutral with regard to jurisdictional claims in published maps and institutional affiliations.

Received: 10 May 2018 Accepted: 21 August 2018

Published online: 31 August 2018

\section{References}

1. Frenzel L. Mast cells and inflammation. Joint Bone Spine. 2013:80:141-5.

2. Silver R. Mast cells on the mind: new insights and opportunties. Trends Neurosci. 2013;36:513-21.

3. Li NN, Zhang X, Dong HQ, Hu YL, Qian YN. Bidirectional relationship of mast cells-neurovascular unit communication in neuroinflammation and its involvement in POCD. Behav Brain Res. 2017;322:60-9.

4. Zhang SS, Dong HQ, Zhang X, Li NN, Sun J, Qian YN. Cerebral mast cells contribute to postoperative cognitive dysfunction by promoting blood brain barrier disruption. Behav Brain Res. 2016;298:158-66.

5. Liu X, Wang JL, Zhang HY, Zhan MM, Chen HQ, Fang ZM, Xu CY, He SH. Induction of mast cell accumulation by tryptase via a protease activated receptor-2 and ICAM-1 dependent mechanism. Mediat Inflamm. 2016;2016: 6431574.

6. He S. Human mast cell tryptase: a stimulus of microvascular leakage and mast cell activation. Eur J Pharmacol. 1997;328:89-97.

7. Meyer MC, Creer MH. Potential role for mast cell tryptase in recruitment of inflammatory cells to endothelium. Am J Physiol Cell Physiol. 2005;289: C1485-91.

8. Malamud V, Vaaknin A, Abramsky O, Mor M, Burgess LE, Ben-Yehudan A, Lorberboum-Galski H. Tryptase activates peripheral blood mononuclear cells causing the synthesis and release of TNF-alpha, IL-6 and IL-1 beta: possible relevance-to multiple sclerosis. J Neuroimmunol. 2003;138:115-22.

9. Zeng XN, Zhang $\mathrm{S}, \mathrm{Xu} \mathrm{LW}$, Yang HW, He SH. Activation of proteaseactivated receptor 2-mediated signaling by mast cell Tryptase modulates cytokine production in primary cultured astrocytes. Mediat Inflamm. 2013; 2013:140812.

10. Zhang S, Zeng XN, Yang HW, Hu G, He SH. Mast cell tryptase induces microglia activation via protease-activated receptor 2 signaling. Cell Physiol Biochem. 2012;29(5-6):931-40.

11. Luo W, Wang Y, Reiser G. Protease-activated receptors in the brain: receptor expression, activation, and functions in neurodegeneration and neuroprotection. Brain Res Rev. 2007;56(2):331-45.

12. Hanusova Z, Mosko T, Matej R, Holada K. Precision in the design of an experimental study deflects the significance of proteinase-activated receptor 2 expression in scrapie-inoculated mice. J Gen Virol. 2017;98(6):1563-9.

13. Park GH, Jeon SJ, Ko HM, Ryu JR, Lee JM, Kim HY, Han SH, Kang YS, Park SH, Shin CY, Ko KH. Activation of microglial cells via protease-activated receptor 2 mediates neuronal cell death in cultured rat primary neuron. Nitric Oxide. 2010;22(1):18-29.

14. Dömötör E, Bartha K, Machovich R, Adam-Vizi V. Protease-activated receptor-2 (PAR-2) in brain microvascular endothelium and its regulation by plasmin and elastase. J Neurochem. 2002;80(5):746-54.

15. Rosas-Hernandez H, Cuevas E, Lantz SM, Lantz SM, Paule MG, Ali SF. Isolation and culture of brain microvascular endothelial cells for in vitro blood-brain barrier studies. Methods Mol Biol. 2018, 1727:315-31.

16. Mehrabadi AR, Korolainen MA, Odero G, Miller DW, Kauppinen TM. Poly(ADP-ribose) polymerase-1 regulates microglia mediated decrease of endothelial tight junction integrity. Neurochem Int. 2017;108:266-71.

17. Si MY, Jiao XY, Li YZ, Chen HZ, He P, Jiang F. The role of cytokines and chemokines in the microenvironment of the blood-brain barrier in leukemia central nervous system metastasis. Cancer Manag Res. 2018;10:305-13.

18. Pan Y, Sun X, Jiang L, Hu L, Kong H, Han Y, Qian C, Song C, Qian Y, Li-U W. Metformin reduces morphine tolerance by inhibiting microglial-mediated neuroinflammation. J Neuroinflammation. 2016;13:294.

19. MD S, Sagare AP. Blood-brain barrier breakdown in Alzheimer disease and other neurodegenerative disorders[]. NaturereviewsNeurology. 2018;14(3):133-50.

20. Montagne A, Zhao Z. Alzheimer's disease: a matter of blood-brain barrier dysfunction[J]. J Exp Med. 2017;214(11):3151-69.

21. Lindsberg PJ, Strbian D, Karjalainen-Lindsberg M-L. Mast cells as early responders in the regulation of acute blood-brain barrier changes after cerebral ischemia and hemorrhage. J Cereb Blood Flow Metab. 2010;30(4):689-702.

22. Mattila OS, Saksi J, Tero O, Pikkarainen VR, Tatlisumak T, Lindsberg PJ. Cerebral mast cells mediate blood-brain barrier disruption in acute 
experimental ischemic stroke through perivascular gelatinase activation. Stroke. 2011;42(12):3600-5.

23. Gustavsson C, Agardh CD, Zetterqvist AV, Nilsson J, Agardh E, Gomez MF. Vascular cellular adhesion molecule-1 (VCAM-1) expression in mice retinal vessels is affected by both hyperglycemia and hyperlipidemia. PLoS One. 2010;5:e12699.

24. Wojkowska DW, Szpakowski P, Glabinski A. Interleukin 17A promotes lymphocytes adhesion and induces CCL2 and CXCL1 release from brain endothelial cells. Int J Mol Sci. 2017;18(5):1000.

25. Breuer J, Herich S, Schneider-Hohendorf T, Chasan Al, Wettschureck N, Gross CC, Loser K, Zarbock A, Roth J, Klotz L, Wiendl H, Schwad N. Dual action by fumaric acid esters synergistically reduces adhesion to human endothelium. Mult Scler. 2017;1352458517735189.

26. Kempuraj D, Selvakumar GP, Zaheer S, Thangavel R, Ahmed ME, Raikwar S, Govindarajan R, lyer S, Zaheer A. Cross-Talk between Glia, Neurons and Mast Cells in Neuroinflammation Associated with Parkinson's Disease. J Neuroimmune Pharmacol. 2018;13(1):100-12.

27. Weekman EM, Wilcock DM. Matrix metalloproteinase in blood-brain barrier breakdown in dementia. J Alzheimers Dis. 2016;49(4):893-903.

28. Birkedal-Hansen H. Role of Matrix Metalloproteinases in Human Periodontal Diseases. J Periodontol. 1993;64(Suppl 5S):474-84.

29. Ribatti D, Ranieri G. Tryptase, a novel angiogenic factor stored in mast cell granules. Exp Cell Res. 2015;332:157-62.

30. Choi KH, Kim HS, Park MS, Lee EB, Lee JK, Kim JT, Lee MC, Lee HJ, Cho KH. Overexpression of caveolin-1 attenuates brain edema by inhibiting tight junction degradation. Oncotarget. 2016;7:67857-67.

31. Caffo M, Esposito E, Barresi V, Cardali SM, Rinaldi M, Mallamace R, Campolo M, Casili G, Conti A, Germano A, Cuzzocrea S, Minutoli L. Modulation of Dkk3 and claudin-5 as new therapeutic strategy in the treatment of meningiomas. Oncotarget. 2017;8:68280-90.

32. Chui R. Regulation of CCL2 and CCL3 expression in human brain e- ndothelial cells by cytokines and lipopolysaccharide. J Neuroinflammation. 2010;7:1.

33. Khedr MMS, Abdelmotelb AM, Pender SLF, Zhou X, Walls AF. Neutrophilia, gelatinase release and microvascular leakage induced by human mast cell tryptase in a mouse model: lack of a role of protease activated receptor 2 (PAR2). Clin Exp Allergy. 2018;48(5):555-67.

34. Jiang Y, Yau MK, Kok WM, Lim J, Wu KC, Liu L, Hill TA, Suen JY. Fairlie DP Biased Signaling by Agonists of Protease Activated Receptor 2. ACS Chem Biol. 2017:12:1217-26.

35. Park Y, Yang J, Zhang $\mathrm{H}$, Chen $\mathrm{XN}$, Zhang $\mathrm{CH}$. Effect of PAR2 in regulating TNF- $a$ and NAD(P)H oxidase in coronary arterioles in type 2 diabetic mice. Basic Res Cardiol. 2011;106:111-23.

36. Fei Y, Sun L, Yuan C, Jiang M, Lou Q, Xu Y. CFTR ameliorates high glucose-induced oxidative stress and inflammation by mediating the NF-KB and MAPK signaling pathways in endothelial cells. Int. J Mol Med. 2018:41(6):3501-8

Ready to submit your research? Choose BMC and benefit from:

- fast, convenient online submission

- thorough peer review by experienced researchers in your field

- rapid publication on acceptance

- support for research data, including large and complex data types

- gold Open Access which fosters wider collaboration and increased citations

- maximum visibility for your research: over $100 \mathrm{M}$ website views per year

At $\mathrm{BMC}$, research is always in progress.

Learn more biomedcentral.com/submissions 